\title{
A Rare Case of Fatal Left Ventricular Free Wall Rupture: Case Report and Short Review
}

Mahmoud Abdelnaby ${ }^{1 *}$, Abdallah Almaghraby², Yehia Saleh², Muhammad Abdul Haleem ${ }^{3}$, Ashraf ElAmin² and Basma Hammad $^{4}$

${ }^{1}$ Cardiology and Angiology Unit, Department of Clinical and Experimental Internal Medicine, Medical Research Institute, University of Alexandria, Egypt ${ }^{2}$ Department of Cardiology, University of Alexandria, Egypt

${ }^{3}$ Department of Emergency Medicine, University of Alexandria, Egypt

${ }^{4}$ Massachusetts General Hospital, Boston, USA

\section{Abstract}

Left ventricular free wall rupture (LVFWR) is a rare, yet lethal, complication of acute myocardial infarction (AMI), occurring in approximately $2 \%$ of cases. In the era of percutaneous coronary intervention, however, it is less frequently encountered.

We were confronted with a case of AMI complicated with LVFWR after receiving thrombolytic therapy. The diagnosis was established using transthoracic echocardiography (TTE). Unfortunately, the patient passed away before surgical intervention. This case demonstrates the importance of prompt diagnosis and management of such a lethal complication.

Keywords: Left Ventricular Free Wall Rupture (LVFWR); Myocardial Infarction (MI); Thrombolysis; Percutaneous Coronary Intervention (PCI).

\section{Introduction}

Left ventricular free wall rupture (LVFWR) is a rare complication of acute myocardial infarction (AMI), occurring in approximately $2 \%$ of cases [1]. However, due to progressive advances in the field of percutaneous coronary interventions, LVFWR is becoming exceedingly rare [2]. Yet, still it is considered one of the most fatal complications of AMI [3] (Figures 1 and 2).

\section{Case Report}

A 65-year-old male patient, current smoker, with no past medical

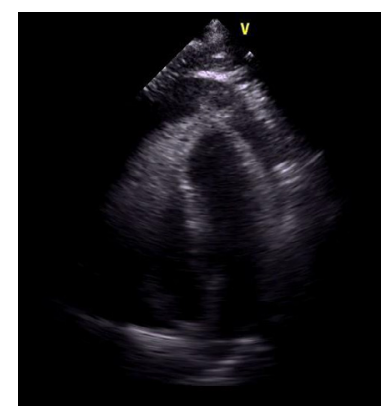

Figure 1: TTE apical 4 chamber view showing a circumferential pericardial effusion.

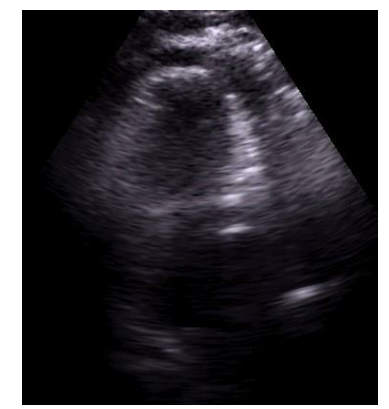

Figure 2: TTE apical 4 chamber view showing apical LVFWR.

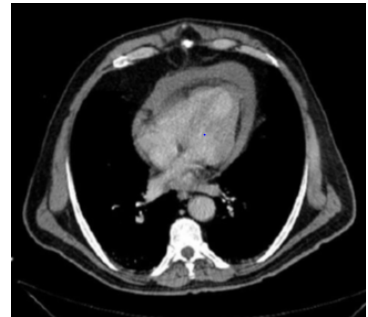

Figure 3: Non-contrast MSCT chest showing area of ventricular rupture.

or surgical history. presented to a primary health care hospital complaining of severe typical chest pain that has been present for 6 hours. His electrocardiogram (ECG) showed extensive anterior myocardial infarction. The patient received thrombolytic therapy (streptokinase), however, the patient continued to have chest pain and the ST segment elevation did not resolve. Consequently, the patient was transferred to a tertiary care centre (Figures 3 and 4 ).

Upon arrival, the patient still had ongoing chest pain, he had stable hemodynamic and follow-up ECG showed sinus tachycardia, lowvoltage QRS complexes with diffuse ST segment elevation in anterior chest leads and no electrical alternans. Bedside TTE revealed large nontamponading pericardial effusion with suspected left ventricular (LV) free wall rupture. Multi-slice Computed Tomography (MSCT) scan of the heart with contrast revealed massive pericardial effusion and sealed left ventricular free wall rupture with a hematoma (Figures 5 and 6).

While the patient was being prepared for urgent surgery, he started

*Corresponding author: Mahmoud Abdelnaby, Cardiology and Angiology Unit, Department of Clinical and Experimental Internal Medicine, Medical Research Institute, University of Alexandria, Egypt, Tel: +20 3 5921675; E-mail: mahmoud.hassan.abdelnabi@outlook.com

Received July 05, 2017; Accepted July 31, 2017; Published August 07, 2017

Citation: Abdelnaby M, Almaghraby A, Saleh Y, Haleem MA, El Amin A, et al. (2017) A Rare Case of Fatal Left Ventricular Free Wall Rupture: Case Report and Short Review. J Cardiovasc Dis Diagn 5: 290. doi: 10.4172/2329-9517.1000290

Copyright: (c) 2017 Abdelnaby M, et al. This is an open-access article distributed under the terms of the Creative Commons Attribution License, which permits unrestricted use, distribution, and reproduction in any medium, provided the original author and source are credited. 
Citation: Abdelnaby M, Almaghraby A, Saleh Y, Haleem MA, El Amin A, et al. (2017) A Rare Case of Fatal Left Ventricular Free Wall Rupture: Case Report and Short Review. J Cardiovasc Dis Diagn 5: 290. doi: 10.4172/2329-9517.1000290

Page 2 of 2

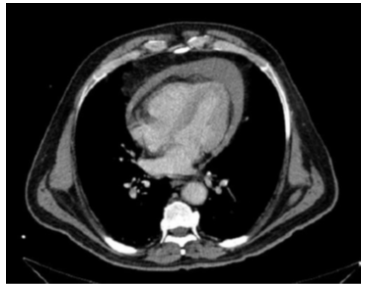

Figure 4: Non-contrast MSCT chest showing area of massive pericardial effusion

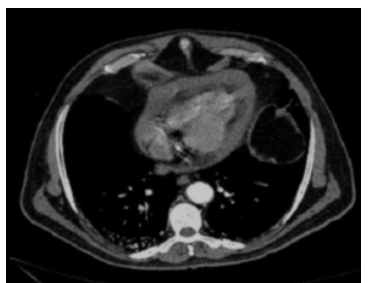

Figure 5: Contrast MSCT chest showing sealed ventricular rupture with a hematoma.

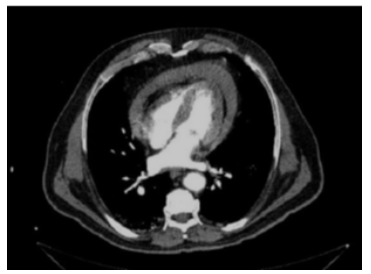

Figure 6: Contrast MSCT chest showing sealed ventricular rupture with a massive pericardial effusion.

to be lethargic and sweaty, he developed bilateral jugular venous congestion and progressive hypotension. Cardiac auscultation revealed no audible rub or gallop and no new murmurs, follow-up TTE revealed tamponading pericardial effusion. Emergency peri cardiocentesis was attempted while transferring the patient to the operating room but unfortunately, the patient developed asystole and died.

\section{Discussion}

LVFWR is a rare but devastating complication of AMI [3] diagnosis depends on a high index of suspicion as well as close monitoring of patient's symptoms and signs [4-6]. TTE is considered the gold standard for diagnosis of mechanical complications of AMI such as LVFWR [7]. MSCT may be a suitable alternative if the diagnosis is uncertain or to exclude other causes of hemopericardium [8,9]. Cardiac magnetic resonance (CMR) is mainly used for tissue characterization in patients with subacute LVFWR or pseudoaneurysm who are clinically stable $[10,11]$.

Despite the high risk of operative mortality, urgent surgical repair is still the definitive treatment. The usual approach is pericardial patch closure of the defect or, less frequently, infarctectomy with patch placement and ventricular wall reconstruction [12-14]. Pericardiocentesis should be done only as an emergency desperate measure if cardiac tamponade occurs while a surgical repair is planned $[15,16]$.

\section{Conclusion}

LVFWR is a catastrophic complication of AMI which is rarely seen nowadays. Prompt diagnosis is mandatory, urgent surgical repair is necessary to reduce its fatality.

\section{References}

1. Moreno R, De Sá EL, López-Sendón JL, García E, Soriano J, et al. (2000) Frequency of left ventricular free-wall rupture in patients with acute myocardial infarction treated with primary angioplasty. Am J Cardiol 85: 757-760.

2. Yip HK, Wu CJ, Chang HW, Wang CP, Cheng Cl, et al. (2003) Cardiac rupture complicating acute myocardial infarction in the direct percutaneous coronary intervention reperfusion era. Chest 124: 565-571.

3. Keeley EC, De Lemos JA (2005) Free wall rupture in the elderly: Deleterious effect of fibrinolytic therapy on the ageing heart. Eur Heart J 26: 1693-1694.

4. López-Sendón J, González A, De Sá EL, Coma-Canella I, Roldán I, et al. (1992) Diagnosis of subacute ventricular wall rupture after acute myocardial infarction: sensitivity and specificity of clinical, hemodynamic and echocardiographic criteria. J Am Coll Cardiol 19: 1145-1153.

5. Oliva PB, Hammill SC, Edwards WD (1993) Cardiac rupture, a clinically predictable complication of acute myocardial infarction: Report of 70 cases with clinicopathologic correlation. J Am Coll Cardiol 22: 720-726.

6. Figueras J, Curós A, Cortadellas J, Soler-Soler J (1996) Reliability of electromechanical dissociation in the diagnosis of left ventricular free wall rupture in acute myocardial infarction. Am Heart J 131: 861-864.

7. Mittle S, Makaryus AN, Mangion J (2003) Role of contrast echocardiography in the assessment of myocardial rupture. Echocardiography 20: 77-81.

8. Suzuki R, Mikamo A, Kurazumi H, Hamano K (2010) Left ventricular free wal rupture detected by multidetector computed tomography after mitral valve replacement. J Card Surg 25: 699.

9. Crossley RA, Morgan-Hughes GJ, Roobottom CA (2007) Post myocardia infarction left ventricular free wall rupture diagnosed by multidetector computed tomography. Heart 93: 653.

10. Shiozaki AA, De Faria Filho RA, Oliveira Dallan LA, De Oliveira SA, Nicolau JC et al. (2007) Left ventricular free-wall rupture after acute myocardial infarction imaged by cardiovascular magnetic resonance. J Cardiovasc Magn Reson 9: 719-721.

11. Krishnan U, McCann GP, Hickey M, Schmitt M (2008) Role of contrastenhanced magnetic resonance imaging in detecting early adverse remodeling and subacute ventricular wall rupture complicating myocardial infarction. Heart Vessels 23: 430-432

12. Park WM, Connery CP, Hochman JS, Tilson MD, Anagnostopoulos CE (2000) Successful repair of myocardial free wall rupture after thrombolytic therapy for acute infarction. Ann Thorac Surg 70: 1345-1349.

13. Reardon MJ, Carr CL, Diamond A, Letsou GV, Safi HJ, et al. (1997) Ischemic left ventricular free wall rupture: Prediction, diagnosis, and treatment. Ann Thorac Surg 64: 1509-1513.

14. Sutherland FW, Guell FJ, Pathi VL, Naik SK (1996) Post infarction ventricular free wall rupture: Strategies for diagnosis and treatment. Ann Thorac Surg 61: 1281-1285.

15. Purcaro A, Costantini C, Ciampani N, Mazzanti M, Silenzi C, et al. (1997) Diagnostic criteria and management of subacute ventricular free wall rupture complicating acute myocardial infarction. Am J Cardiol 80: 397-405.

16. Figueras J, Cortadellas J, Evangelista A, Soler-Soler J (1997) Medica management of selected patients with left ventricular free wall rupture during acute myocardial infarction. J Am Coll Cardiol 29: 512-518. 